\title{
Comparative Study between Intrathecal and Caudal Epidural Anesthesia in Children for Lower Abdominal Surgery
}

\author{
Mostafa Mohammed Mahdy, Maamon Mohammed Ismail, Amr Soliman Hamrosh, Ahmed \\ Elsayed Kamel Elfiky \\ Department of Anaesthesia and Intensive Care, Faculty of Medicine - Al Azhar University \\ *Corresponding author: Ahmed Elsayed Kamel Elfiky, Mobile: 01007085123, E-Mail: magdi. arabicwolrd@ gmil.com
}

\begin{abstract}
Background: regional anaesthesia techniques are now established in the practice of pediatric anaesthesia. It is one of the most common techniques used for post-operative pain management in pediatric patients especially for urogenital, rectal, inguinal and lower extremity surgeries.

Objective: to compare caudal and spinal anaesthesia in paediatrics regarding haemodynamics, efficacy (sensory block characteristics, motor block characteristics) post-operative analgesia, surgeon's satisfaction, parents' satisfaction and complications incidence.

Material and Methods: the present study was carried on100 patients, with age ranging from (6-12) and of ASA(american society of anaesthesia.) I, II classes undergoing infraubmliclal pediatric surgeries, patients in each group were randomly assigned to receive spinal or caudal epidural anaesthesia.

Results: the demographic data of patients as regard age, sex and ASA classification showed no statistical significant difference between the two groups, where the study was designed to compare between the effectiveness of spinal anaesthesia with bupivacaine $0.3 \mathrm{mg} / \mathrm{kg}$ and caudal anaesthesia with bupivacaine $2 \mathrm{mg} / \mathrm{kg}(1 \mathrm{ml} / \mathrm{kg}$ vol.) as a sole anaesthetic technique adequate for infraumblical pediatric surgeries below $\mathrm{T} 10$ as regard the sensory and motor block characteristics, perioperative haemodynamic effects, pain assessment, analgesic requirements, and both the surgeon ad parents satisfaction was assessed.the results showed the superiority of subarachnoid on achieving rapid onset of sensory blockade, intense motor blockade, on the other hand the caudal epidural had the advantage of longer post-operative analgesic effect and lower post-operative analgesic consumption, furthermore both techniques gained good degree of parent and surgeon satisfaction.
\end{abstract}

Conclusion: if both techniques are correctly used and the anatomy of the patient is normal there is minimal risk of complications.

Key words: intrathecal, caudal epidural, infraumblical, pediatric surgeries.

\section{INTRODUCTION}

The appearance of neuromuscular blocking agents and the development of volatile anesthetics in the forties shifted the techniques toward general anesthesia. However, regional pediatric anesthesia did not disappear ${ }^{(\mathbf{1})}$.

Both spinal and caudal anaesthetic blocks can be given easily in combination with G.A(general anesthesia) or as the sole to provide anaesthesia and additional postoperative analgesia especially for infraumlical lower abdominal pediatric surgeries (block below T10), furthermore both technique can replace G.A in circumstances where is shortage of anaesthetic drugs, supplies and monitoring equipment which are not available especially in the developing countries ${ }^{(2)}$.

There are advantages to use regional anaesthesia that are evident and continue to increase the popularity of its practice. One of the valuable goals during anaesthetic management is to achieve safety and reliability (3).

The common advantages of spinal anaesthesia are adequate anaesthesia without polypharmacy, endotracheal intubation and respiratory support, minimal biochemical and physiological differences, post-operative analgesia, absence of post-operative nausea and vomiting, rapid return of feeding, minimal postoperative apnoeic spells, low cost, reduction in post-operative hospital admissions in an outpatients population ${ }^{(3)}$.

Spinal anesthesia though gaining popularity in children, the misconceptions regarding its safety and feasibility can be better known with greater use and experience ${ }^{(4)}$.

Caudal anesthesia was first described at the turn of last century by two French physicians, Fernand Cathelin and JeanAnthanase Sicard (4). Today pediatric caudal 
epidural anesthesia is a well-accepted technique, and considered one of the most usedpopular regional blocks in children. This technique is a useful adjunct during general anesthesia and for providing postoperative analgesia after infraumbilical operations. The quality and level of the caudal blockade is dependent on the dose, volume, and concentration of the injected drug ${ }^{(4)}$.

Caudal anesthesia can be easily modified to extend analgesia into the postoperative period by addition of opioids or insertion of caudal epidural catheter in the caudal canal for continuous techniques ${ }^{(2)}$.

\section{AIM OF THE WORK}

Our aim is to compare caudal and spinal anaesthesia in pediatrics regarding haemodynamics, efficacy (sensory block characteristics, motor block characteristics) post-operative analgesia, surgeon's satisfaction, parents' satisfaction and complications incidence.

\section{MATERIAL AND METHODS}

After approval of Ethical Committee of Al-Azhar Faculty of Medicine, a prospective, randomized, double blinded study was conducted in the department of Anesthesia, Al- Azhar University (Al-Husien and Bab- Alshaeria) hospitals.

One hundred patients of both sex, aged 6-12 years, ASA grade I, II, weight $(20-50 \mathrm{~kg})$ scheduled for lower abdominal procedures requiring sensory block below $\mathrm{T} 10$ which last for at least one hour were enrolled in our study.

Patients were divided randomly into two groups according to the type of regional anesthesia given spinal group or caudal group.

All patients were evaluated preoperatively by taking full medical history, physical examination including vital signs, cardiovascular, respiratory, abdomen, neurological, airway evaluation and laboratory investigations as full blood picture, bleeding and coagulation profiles.

Patients with any contraindication to regional anesthesia as those with known allergy to local anaesthetic drugs, weight $>50 \mathrm{~kg}$, coagulopathy, infection at the site of block, spine deformity, history of developmental delay, were excluded from the study.

Before the operation the patient received instruction about the colour analogue scale (CAS). The colour analogue scale has been shown to be a valid and reliable pain measurement tool for use in children aged above 6 years ${ }^{(7)}$.

Parents were informed about anesthetic procedure and the informed consent was taken.

All the patients were kept NPO for 6 hours preoperatively.

\section{Technique:}

Upon arrival to the operating room the ambient temperature was kept warm. Child was monitored for ECG, HR, noninvasive blood pressure $\mathrm{O} 2 \%$ saturation with pulse oximetery (SPO2\%) and the base line values were recorded. After securing an intravenous line access with $22 \mathrm{G}$ IV cannula, all patients were preloaded with lactate ringer solution $10 \mathrm{ml} / \mathrm{kg}$. Atropine $0.01 \mathrm{mg} / \mathrm{kg}$ was given as premedication. In the operating room all the children were received I.V ketamine $2 \mathrm{mg} / \mathrm{kg}$ immediately before spinal or caudal block to achieve immobility of the patient during the block. Subsequently all the children were placed in left lateral position with the hips and knees flexed, painting and draping were done with full aseptic precaution. In all cases, sedation was maintained with propofol infusion (using syringe pump) at the rate of 50-75 $\mathrm{mcg} / \mathrm{kg} / \mathrm{min}$. The spinal group (S) 50 patients were received spinal anaesthesia (Group $S$ $(\mathrm{n}=50)$ ), via midline approach lumbar puncture was done in the L4-5 interspace with $25 \mathrm{G}$ spinal needle with stylette and the direction of the bevel was kept parallel to longitudinal fibres of the dura with spinal anesthesia using heavy bupivacaine $0.5 \%$ in the dose of $(0.3 \mathrm{mg} / \mathrm{kg})$ were injected in the subarachnoid space. The end of injection was considered as time zero for further data recording. The other 50 patients were received caudal epidural anaesthesia (Group C $(\mathrm{n}=50)$ ), the caudal epidural space was entered using a short 23-gauge needle. The needle was inserted at a 60-degree angle and was advanced until a "pop" was felt, then was lowered to a 20-degree angle and was advanced an additional. $2-3 \mathrm{~mm}$ to make sure the bevel is in the caudal epidural space.

Caudal block was done using $0.25 \%$ bupivacaine dose $(2 \mathrm{mg} / \mathrm{kg})$ volume $0.7-1 \mathrm{ml} / \mathrm{kg}$ which was injected slowly in the caudal epidural space. The parents and surgeon who had carried the surgery was blinded to the type of block given to the patient.

Surgical intervention was started after ensuring sensory block. 
Adequate intraoperative analgesia was achieved by hemodynamic stability as indicted by absence of an increase heart rate or systolic blood pressure $>20 \%$ compared with baseline values obtained preoperative.

An increase of blood pressure or heart rate more than $20 \%$ was insufficient analgesia and was treated with opioid (fentanyl $1 \mathrm{mic} / \mathrm{kg}$ ) and the patient was excluded from the study and was transferred to GA and replaced by another patient according to the randomization list.

On the other hand decrease of heart rate more than $20 \%$ from preoperative values was defined as bradycardia. Bradycardia was treated with Atropine as necessary.

Preoperative blood loss was replaced using crystalloid solution and blood (when indicated) as appropriate.

At the begging of skin closure the duration of surgery was recorded.

After the operation the patients were taken to the recovery room for observation and then transferred to the word after achievement of criteria of discharge.

\section{STATISTICAL ANALYSIS:}

Statistical presentation and analysis of the present study will be conducted, using the mean, standered error,chi-square and analysis of variance(ANOVA)tests by SPSSV17.

Chi-square the hyposis that the row and column variables are independent, without indicating strength or direction of the relationship pearson chi-square and likelihood -ratio chi-square. Fisher's exact test and yate's corrected chi-square are computed for $2 \times 2$ tables.

Analysis of variance (ANOVA) tests according to computer programs

SPSS for windows. ANOVA test will be used for comparison among different times in the same group in quantitative data

$P$ value $>0.05$ is considered non-significant

$P$ value $<0.05$ is considered significant

$\mathrm{P}$ value $<0.01$ is considered highiy significant

\section{RESULTS}

Table (1): List of operative procedures in both groups

\begin{tabular}{|l|c|c|c|}
\hline & Spinal & Caudal & P \\
\hline Herniotomy & 15 & 16 & 0.829 \\
\hline Circumcision & 5 & 5 & 1.000 \\
\hline Orchidoplexy & 10 & 9 & 0.799 \\
\hline Hypospadias & 15 & 16 & 0.829 \\
\hline Cystolithotomy & 5 & 4 & 1.000 \\
\hline
\end{tabular}

Table (2): Comparison between the two groups as regard H.R

\begin{tabular}{|c|c|c|c|c|c|}
\hline \multirow{2}{*}{ Heart Rate (beats/min.) } & \multicolumn{2}{|c|}{ Spinal $(S)(n=50)$} & \multicolumn{2}{|c|}{ Caudal $(C)(n=50)$} & \multirow{2}{*}{$\mathbf{P}$} \\
\hline & Mean & p1 & Mean. & p2 & \\
\hline Before block & 72.5 & & 73.3 & & 0.169 \\
\hline 5 Min. & 75.55 & $<0.001 *$ & 77.2 & $<0.001 *$ & 0.101 \\
\hline 10 Min. & 79.72 & $<0.001 *$ & 81.4 & $<0.001 *$ & 0.090 \\
\hline 15 Min. & 82.9 & $<0.001 *$ & 85.6 & $<0.001 *$ & 0.014* \\
\hline 30 Min. & 84 & $<0.001 *$ & 86.7 & $<0.001 *$ & $0.031 *$ \\
\hline 45 Min. & 81 & $<0.001 *$ & 83.9 & $<0.001 *$ & 0.035* \\
\hline 60 Min. & 77.4 & $<0.001 *$ & 80.4 & $<0.001 *$ & 0.021* \\
\hline 90 Min. & 75.2 & $<0.001 *$ & 76.6 & $<0.001 *$ & 0.166 \\
\hline 120 Min. & 73.1 & 0.518 & 74.2 & 0.235 & 0.315 \\
\hline 150 Min. & 72 & 0.500 & 73 & 0.594 & 0.247 \\
\hline 180 Min. & 71.8 & 0.081 & 72.6 & 0.178 & 0.094 \\
\hline 4 hrs. & 71.7 & 0.069 & 72.5 & 0.146 & 0.115 \\
\hline 5 hrs. & 71.9 & 0.147 & 72.7 & 0.221 & 0.166 \\
\hline 6 hrs. & 72 & 0.181 & 72.6 & 0.182 & 0.258 \\
\hline 8 hrs. & 73.5 & 0.094 & 73.8 & 0.445 & 0.732 \\
\hline 10 hrs. & 73.6 & 0.063 & 74.2 & 0.235 & 0.510 \\
\hline 12 hrs. & 72.5 & 0.964 & 73 & 0.594 & 0.405 \\
\hline
\end{tabular}

p: for comparison between the two groups

$p_{1}$ : for comparison between before block with each other periods in Spinal (S) group

p2: comparison between before block with each other periods in Caudal (C)

*: Statistically significant at $\mathbf{p} \leq \mathbf{0 . 0 5}$

Table (3): Comparison between the two groups as regard systolic blood pressure 
Comparative Study between Intrathecal and Caudal Epidural Anesthesia in Children...

\begin{tabular}{|c|c|c|c|c|c|}
\hline \multirow{2}{*}{$\begin{array}{c}\text { Systolic blood pressure } \\
(\mathrm{mmHg})\end{array}$} & \multicolumn{2}{|c|}{ Spinal $(S)(n=50)$} & \multicolumn{2}{|c|}{ Caudal $(C)(n=50)$} & \multirow{2}{*}{$\mathbf{P}$} \\
\hline & Mean & $\mathbf{p}_{1}$ & Mean. & $\mathbf{p}_{2}$ & \\
\hline Before block & 118.4 & & 115.6 & & 0.060 \\
\hline 5 Min. & 110 & $<0.001^{*}$ & 106.6 & $<0.001^{*}$ & 0.100 \\
\hline 10 Min. & 103 & $<0.001^{*}$ & 99.8 & $<0.001^{*}$ & 0.062 \\
\hline 15 Min. & 100.4 & $<0.001^{*}$ & 98 & $<0.001^{*}$ & 0.256 \\
\hline 30 Min. & 100 & $<0.001^{*}$ & 100.8 & $<0.001^{*}$ & 0.626 \\
\hline 45 Min. & 106.6 & $<0.001^{*}$ & 108.4 & $<0.001^{*}$ & 0.162 \\
\hline 60 Min. & 112.2 & $<0.001^{*}$ & 112.2 & $0.012 *$ & 1.000 \\
\hline 90 Min. & 115.6 & $\mathbf{0 . 0 4 2}^{*}$ & 112.2 & $\mathbf{0 . 0 2 3}^{*}$ & 0.130 \\
\hline 120 Min. & 119 & 0.595 & 118 & 0.057 & 0.402 \\
\hline 150 Min. & 119.2 & 0.542 & 117.4 & 0.202 & 0.225 \\
\hline 180 Min. & 119.4 & 0.429 & 117.1 & 0.229 & 0.078 \\
\hline 4 hrs. & 117.4 & 0.417 & 115.6 & 1.000 & 0.107 \\
\hline 5 hrs. & 118.4 & 1.000 & 116 & 0.674 & 0.079 \\
\hline 6 hrs. & 116.8 & 0.159 & 114.8 & 0.438 & 0.136 \\
\hline 8 hrs. & 116.6 & 0.202 & 117.4 & 0.162 & 0.527 \\
\hline 10 hrs. & 119 & 0.595 & 118 & 0.057 & 0.402 \\
\hline 12 hrs. & 119.2 & 0.542 & 117.4 & 0.202 & 0.225 \\
\hline
\end{tabular}

p: for comparison between the two groups

$p_{1}$ : for comparison between before block with each other periods in Spinal (S) group

$p_{2}$ : comparison between before block with each other period in Caudal $(C)$

*: Statistically significant at $\mathbf{p} \leq \mathbf{0 . 0 5}$

Table (4): Comparison between the two groups as regard diastolic blood pressure

\begin{tabular}{|c|c|c|c|c|c|}
\hline \multirow{2}{*}{$\begin{array}{c}\text { Diastolic blood pressure } \\
(\mathrm{mmHg})\end{array}$} & \multicolumn{2}{|c|}{ Spinal (S) $(n=50)$} & \multicolumn{2}{|c|}{ Caudal $(C)(n=50)$} & \multirow{2}{*}{$\mathbf{P}$} \\
\hline & Mean & $\mathbf{p}_{1}$ & Mean \pm SD. & $\mathbf{p}_{2}$ & \\
\hline Before block & 78.2 & & 77 & & 0.445 \\
\hline 5 Min. & 67.4 & $<0.001^{*}$ & 66.2 & $<0.001^{*}$ & 0.369 \\
\hline 10 Min. & 62.2 & $<0.001^{*}$ & 61 & $<0.001^{*}$ & 0.563 \\
\hline 15 Min. & 58.4 & $<0.001^{*}$ & 60 & $<0.001^{*}$ & 0.194 \\
\hline 30 Min. & 60.4 & $<0.001^{*}$ & 61.8 & $<0.001^{*}$ & 0.272 \\
\hline 45 Min. & 66.8 & $<0.001^{*}$ & 68 & $<0.001^{*}$ & 0.367 \\
\hline 60 Min. & 71 & $<0.001^{*}$ & 72.2 & $<0.001^{*}$ & 0.332 \\
\hline 90 Min. & 72 & $<0.001^{*}$ & 73.6 & $0.036^{*}$ & 0.559 \\
\hline 120 Min. & 76 & 0.109 & 77 & 1.000 & 0.450 \\
\hline 150 Min. & 78 & 0.868 & 77 & 1.000 & 0.326 \\
\hline 180 Min. & 77 & 0.771 & 75.8 & 0.382 & 0.192 \\
\hline 4 hrs. & 79 & 0.252 & 76.4 & 0.705 & 0.136 \\
\hline 5 hrs. & 78 & 1.000 & 75.8 & 0.360 & 0.114 \\
\hline 6 hrs. & 76 & 0.197 & 75 & 0.105 & 0.291 \\
\hline 8 hrs. & 78 & 0.868 & 77 & 1.000 & 0.326 \\
\hline 10 hrs. & 77 & 0.771 & 75.8 & 0.382 & 0.192 \\
\hline 12 hrs. & 79.8 & 0.252 & 76.4 & 0.705 & 0.136 \\
\hline
\end{tabular}

Table (5): Comparison between the two groups as regard Onset of sensory block, Duration of sensory block.

\begin{tabular}{|l|c|c|c|}
\hline & Spinal (S) $(\mathbf{n}=\mathbf{5 0})$ & Caudal $(\mathbf{C})(\mathbf{n}=\mathbf{5 0})$ & P \\
\hline Onset of sensory block (Min.) & & & \\
\hline Mean \pm SD. & $3.14 \pm 0.98$ & $9.56 \pm 1.63$ & $<0.001^{*}$ \\
\hline Duration of sensory block (Min.) & & & \\
\cline { 1 - 3 } & & & $<0.001^{*}$ \\
\hline
\end{tabular}

Table (6): Comparison between the two groups as regard Onset, Duration of motor block.

\begin{tabular}{|l|c|c|c|}
\hline & Spinal (S) $(\mathbf{n}=\mathbf{5 0})$ & Caudal $(\mathbf{C})(\mathbf{n}=\mathbf{5 0})$ & P \\
\hline $\begin{array}{l}\text { Onset of motor block (Min.) } \\
\text { Mean } \pm \text { SD. }\end{array}$ & $6.80 \pm 1.21$ & & $<0.001^{*}$ \\
\hline Duration of motor block (Min.) & $124.5 \pm 10.7$ & $14.89 \pm 1.90$ & $<0.001^{*}$ \\
\hline
\end{tabular}

Table (7): Comparison between the two groups as regard the first analgesic rescue Spinal (S) (n=50) 
First analgesic rescue

Min. - Max.

$82.0-120.0$

$101.0-174.0$

$<0.001$

Table (8): Comparison between the two groups as regard Sedation score.

\begin{tabular}{|c|c|c|c|c|c|}
\hline \multirow{2}{*}{ Sedation score } & \multicolumn{2}{|c|}{ Spinal $(S)(n=50)$} & \multicolumn{2}{|c|}{ Caudal $(C)(n=50)$} & \multirow{2}{*}{$\mathbf{P}$} \\
\hline & Median & $p_{1}$ & Median & $p_{2}$ & \\
\hline Before block & 1 & & 1 & & 1.000 \\
\hline 5 Min. & 5 & $<0.001^{*}$ & 5 & $<0.001^{*}$ & 1.000 \\
\hline 10 Min. & 4 & $<0.001^{*}$ & 4 & $<0.001^{*}$ & 1.000 \\
\hline 15 Min. & 4 & $<0.001^{*}$ & 4 & $<0.001^{*}$ & 1.000 \\
\hline 30 Min. & 4 & $<0.001^{*}$ & 4 & $<0.001^{*}$ & 1.000 \\
\hline 45 Min. & 4 & $<0.001^{*}$ & 4 & $<0.001^{*}$ & 0.818 \\
\hline 60 Min. & 3 & $<0.001^{*}$ & 3 & $<0.001^{*}$ & 0.799 \\
\hline 90 Min. & 2 & $<0.001^{*}$ & 2 & $<0.001^{*}$ & 0.508 \\
\hline 120 Min. & 1 & $0.025^{*}$ & 1 & $0.001^{*}$ & 0.103 \\
\hline 150 Min. & 1 & 1.000 & 1 & 1.000 & 1.000 \\
\hline 180 Min. & 1 & 1.000 & 1 & 1.000 & 1.000 \\
\hline 4 hrs. & 1 & 1.000 & 1 & 1.000 & 1.000 \\
\hline 5 hrs. & 1 & 1.000 & 1 & 1.000 & 1.000 \\
\hline 6 hrs. & 1 & 1.000 & 1 & 1.000 & 1.000 \\
\hline 8 hrs. & 1 & 1.000 & 1 & 1.000 & 1.000 \\
\hline 10 hrs. & 1 & 1.000 & 1 & 1.000 & 1.000 \\
\hline 12 hrs. & 1 & 1.000 & 1 & 1.000 & 1.000 \\
\hline
\end{tabular}

Table (9): Comparison between the two groups as regard Parents satisfaction and Surgeon satisfaction

\begin{tabular}{|c|c|c|c|}
\hline & Spinal $(S)(n=50)$ & Caudal $(C)(n=50)$ & $\mathbf{P}$ \\
\hline \multicolumn{4}{|c|}{ Parents satisfaction } \\
\hline Poor & $0(0.0 \%)$ & $0(0.0 \%)$ & \multirow{4}{*}{0.240} \\
\hline Fair & $6(12.0 \%)$ & $9(18.0 \%)$ & \\
\hline Good & $41(82.0 \%)$ & $34(68.0 \%)$ & \\
\hline Excellent & $3(6.0 \%)$ & $7(14.0 \%)$ & \\
\hline \multicolumn{4}{|c|}{ Surgeon satisfaction } \\
\hline Poor & $0(0.0 \%)$ & $0(0.0 \%)$ & \multirow{4}{*}{0.863} \\
\hline Fair & $3(6.0 \%)$ & $5(10.0 \%)$ & \\
\hline Good & $41(82.0 \%)$ & $40(80.0 \%)$ & \\
\hline Excellent & $6(12.0 \%)$ & $5(10.0 \%)$ & \\
\hline
\end{tabular}

Table (10): Comparison between the two groups as regard color anlogue scale(CAS)

\begin{tabular}{|c|c|c|c|}
\hline CAS & Group S & Group c & P-value \\
\hline $30 \mathrm{~min}$ & 0 & 0 & $0.001 *$ \\
\hline $60 \mathrm{~min}$ & 0 & 0 & $0.001 *$ \\
\hline $90 \mathrm{~min}$ & 2 & 0 & 0.010 \\
\hline $120 \mathrm{~min}$ & 2.5 & 2 & 0.010 \\
\hline $150 \mathrm{~min}$ & 2.5 & 2 & 0.010 \\
\hline $180 \mathrm{~min}$ & 3 & 2.5 & 0.39 \\
\hline 4hours & 3.5 & 3 & 0.39 \\
\hline 5 hours & 3 & 2.5 & 0.370 \\
\hline 6hours & 2.5 & 2 & 0.370 \\
\hline 7 hours & 3 & 2.5 & 0.193 \\
\hline 8 hours & 2.5 & 3 & 0.193 \\
\hline 9 hours & 3.5 & 3 & 0.205 \\
\hline 10 hours & 3 & 2.5 & 0.138 \\
\hline 11 hours & 4 & 3.5 & 0.138 \\
\hline hours12 & 4 & 3.5 & 0.138 \\
\hline
\end{tabular}

Statistically significant at $\mathrm{p} \leq \mathbf{0 . 0 5}$

Table (11): Comparison between the two groups as regard CAS

\begin{tabular}{|c|c|c|c|}
\hline CAS & Group S & Group c & P-value \\
\hline
\end{tabular}




\begin{tabular}{|l|c|c|c|}
\hline $\mathbf{3 0} \mathbf{m i n}$ & 0 & 0 & $0.001 *$ \\
\hline $\mathbf{6 0} \mathbf{m i n}$ & 0 & 0 & $0.001^{*}$ \\
\hline $\mathbf{9 0} \mathbf{m i n}$ & 2 & 0 & 0.010 \\
\hline $\mathbf{1 2 0} \mathbf{m i n}$ & 2.5 & 2 & 0.010 \\
\hline $\mathbf{1 5 0} \mathbf{~ m i n}$ & 2.5 & 2 & 0.010 \\
\hline $\mathbf{1 8 0} \mathbf{m i n}$ & 3 & 2.5 & 0.39 \\
\hline 4hours & 3.5 & 3 & 0.39 \\
\hline $\mathbf{5}$ hours & 3 & 2.5 & 0.370 \\
\hline 6hours & 2.5 & 2 & 0.370 \\
\hline 7 hours & 3 & 2.5 & 0.193 \\
\hline $\mathbf{8}$ hours & 2.5 & 3 & 0.193 \\
\hline $\mathbf{9}$ hours & 3.5 & 3 & 0.205 \\
\hline $\mathbf{1 0}$ hours & 3 & 2.5 & 0.138 \\
\hline $\mathbf{1 1}$ hours & 4 & 3.5 & 0.138 \\
\hline hours12 & 4 & 3.5 & 0.138 \\
\hline
\end{tabular}

Statistically significant at $\mathrm{p} \leq \mathbf{0 . 0 5}$.

Table (12): Comparison between the two groups as regard Total iv. Paracetamol Consumption (mg/12)

\begin{tabular}{|l|c|c|c|}
\hline & Group S (n= 50) & Group C (n= 50) & p-value \\
\hline $\begin{array}{l}\text { Comparison between the two } \\
\text { groups as regard Total iv. } \\
\begin{array}{l}\text { Paracetamol } \\
\text { (mg/12hr.) }\end{array}\end{array} \quad 398 \pm 127$ & $242 \pm 125$ & $<0.001 *$ \\
\hline
\end{tabular}

Table (13): Comparison between the two groups as regard complications.

\begin{tabular}{|l|c|c|}
\hline \multicolumn{2}{|c|}{ Group S } & Group C \\
\hline Systemic toxicity & 0 & 0 \\
\hline Neurotoxicity & 0 & 0 \\
\hline Bradycardia & 4 & 1 \\
\hline Nauea, vomiting & 2 & 0 \\
\hline Hypotension & 2 & 1 \\
\hline Failed block & 2 & 2 \\
\hline
\end{tabular}

\section{DISCUSSION}

In our developing countries there are a lot of challenges in anaesthetic drugs, supplies and monitoring equipments ${ }^{(4)}$.

Some of these challenges can be overcame by choice of safe, reliable and effective sole anaesthetic technique which can provide both anaesthetic and analgesic satisfactory effects for performing the surgical procedure and capable of replacing the general anaesthesia in these situations. Nowadays regional anaesthesia techniques are well established in the practice of pediatric anaesthesia ${ }^{(3)}$.

The present study was designed to compare between the spinal anaesthesia with bupivacaine $0.3 \mathrm{mg} / \mathrm{kg}$ and caudal anaesthesia with bupivacaine $2 \mathrm{mg} / \mathrm{kg}(0.7-1 \mathrm{ml} / \mathrm{kg}$ vol.) as a sole anaesthetic technique adequate for infraumlical paediatric surgeries below T10 as regard the sensory and motor block characterestics, perioperative haemodynamic effects, postoperative analgesia and both the surgeon ad parents satisfaction were assessed.
The targeted level of sensory block was achieved below T8 in spinal group and below T10 in caudal group which provided both sensory, motor blockade allowing performing surgical procedure without facing any complications.

The present study was carried on 100 patients with age ranging from (6-12), and of ASAI, II classes undergoing infraubmliclal paediatric surgeries.

Patients in each group were randomly assigned to receive spinal or caudal epidural anaesthetia.

The demographic profile of our patients and the mean duration of surgery were almost comparable in all groups with no significant statistical difference between the two groups ( $p>.05)$ however more male patients were selected in both groups as many surgeries were male specific, the result was quite similar with other research investigations ${ }^{(1,3)}$.

Regarding the hemodynamics in the present study, the H.R was kept around normal 
range this is because regional anaesthesia abolishes the bradycardiac response to spermatic cord or mesenteric manipulations during lower abdominal surgeries ${ }^{(5)}$.

This result was agreed with the study done by Patel and Thacher ${ }^{(4)}$ and Saikia $\boldsymbol{e t}$ al. (6).

While the bl.p was significantly decreased at 5 minutes up to 90 minutes but still within normal accepted range, this is explained by that sympathetic vascular tone in children at rest is less than in adults. Similar results were observed by Pandya et al. ${ }^{(1)}$.

As regard the onset of sensory blockade, it was longer in caudal $(9.5 \pm 1.6)$ than spinal $(3.1 \pm 0.9)$, furthermore duration of sensory blockade was longer in caudal group $(119 \pm 10.8 \mathrm{~min}$.$) than spinal group (91.8 \pm$ $13 \mathrm{~min}$ ), however as age and weight of the patient decreases duration of both the blocks tends to decrease, this is explained by that myelination of nerve is not complete until 12 years of age, the unmyelinated nerve fibre are capable of relaying information slower than the myelinated fibres, also incomplete myelination allows for better penetration of L.A into nerve fibres, reduced milligram doses of local anaesthetic solutions can provide a complete block in children, in addition to loose fascial attachment around nerve facilitate the spread of L.A consequently regional block in children may spread further than the provider intends, additionally because L.A spreads easily in children the duration of block may be shortened compared to an adult ${ }^{(4)}$.

This was explained by that subarachnoid anaesthesia has the advantage that the block is effective within the first2 minutes compared to caudl which wait for about 10 minutes.

These results were coincided with the results of Pandya and colleagues ${ }^{(1)}$ and with the results reported by Ebrahim et al. (7) reported longer duration of sensory block in caudal group (186.3 $\mathrm{min}$ ) than revealed in our study $(119 \pm 1.8)$.

This difference may be attributed to the difference in the dose of bupivacaine $(15 \mathrm{ml}$ of $5 \%$ bupiavcaine) that he used in his study.

Regarding the motor blockade characteristics, onset of motor blockade was longer in caudal group $(11.8 \pm 1.9)$ than spinal group $(6.8 \pm 1.2)$, furthermore the duration of motor blockade in caudal results were coincided with the results of Pandya et al. ${ }^{(1)}$. Similar results were obtained by Patel and Thacher ${ }^{(4)}$.

Ebrahim et al. (7) reported longer duration of onset of motor blockade in caudal group (26min). This difference with the results of the current study may be attributed to the difference in the dose of bupivacaine that used in both studies.

Regarding the complications, the spinal group reported $4 / 50(8 \%)$ had bradycardia, $2 / 50$ (4\%) cases had hypotension, $2 / 50(4 \%)$ cases had nausea and vomiting, 2/50(4\%) cases had failed block, the caudal group reported $1 / 50(2 \%)$ case hypotension, $1 / 50(2 \%)$ cases had failed block. No systemic toxicity, neurotoxicity were reported in both techniques, No local infection was reported most probably because of aseptic cleaning before the puncture. Complications Were treated symptomatically: bradycardia were treated by atropine $0.01 \mathrm{mg} / \mathrm{kg}$, nausea and vomiting were treated by antiemetics (metoclopromide $0.2 \mathrm{mg} / \mathrm{kg}$ ), hypotension was treated by crystalloid solutions and ephedrine as appropriate, cases of post spinal headache were treated by bed rest, cafeine and analgesia as need, while cases of failed block were transferred to GA and were excluded from the study. Similar results were reported by Patel and Thacher ${ }^{(4)}$ in their study.

\section{CONCLUSION}

Both techniques are safe effective ad satisfactory as a sole anesthetic technique under sedation and have the capability of replacing the G.A especially in infraumblical pediatric surgeries below T10 level with the superiority of subarachnoid on achieving rapid onset of sensory blockade, intense motor blockade, on the other hand the caudal epidural had the advantage of longer post-operative analgesic effect and lower post-operative analgesic consumption, furthermore both techniques gained good degree of parent and surgeon satisfaction.

\section{REFERENCES}

1. Pandya C, Kirtipatel K, Panchasara K (2014): Comparative study between pediatric spinal and caud. NHL., 3:72-76. 
2. Elder A and Vinit G (1998): Caudal epidural anesthesia for pediatric pts. Update in Anesthesia, 8: 15-19.

3. Shah $N$ and Patel I (2015): comparison of general $\mathrm{v} / \mathrm{s}$ caudal epidural in infraumplical surgeries. I J Biomedical Research, 6: 35-39.

4. Patel $N$ and Thacher $M$ (2015): Comparative study between pediatric spinal and caudal anaesthesia. IJSR.,4: 313-315

5. Johr $M$ and Berger TM (2012): Caudal blocks in pediatrics. Pediatric Anaesthesia, 22: $44-50$.
6. Saikia A, diganta B, Arnav D (2016): pradip: onset and duration of sensory and motor blockade of bupivacaine supplemented with clonidine and dexmedetomidine administered intrathecally -Aclinical comparative study. IJCMR., 3:1906-1908.

7. Ebrahim KT, Charlisthomas M, Sanjavinod A (2016): Comparison of onset and duration of sensory and motor block with bupivacaine $0.5 \%$ and ropivacaine $0.75 \%$ in epidural anaesthesia. OSR., 15: 60-64. 